\title{
Л.А. Кутилова
}

\section{ЭТНИЧЕСКАЯ МОБИЛИЗАЦИЯ В 1917 г.: СЬЕЗД НАРОДОВ РОССИИ И ЕГО ИДЕИ ТРАНСФОРМАЦИИ ГОСУДАРСТВЕННОГО УСТРОЙСТВА}

\begin{abstract}
Рассматривается обсуждение вопросов государственного устройства России на Съезде народов в сентябре 1917 г. в Киеве. Это собрание представлено как форум этнических элит, выступающих за федерализацию страны с позиции диалога с Временным правительством; анализируются причины, которые в 1917 г. предопределили невостребованность идеи в рамках процесса модернизации. Исследование основано на архивных, мемуарных источниках, материалах газет.

Ключевые слова: 1917 г.; Съезд народов; этническая мобилизация; проекты модернизации; федерализм.
\end{abstract}

Важнейшей формой этнической мобилизации в 1917 г. стали разного рода съезды, которые до созыва Учредительного собрания рассматривались как единственно верный путь национально-региональной самоорганизации, особенно в западных областях России, охваченных войной. Народные массы отказывались принимать тактику ожидания Учредительного собрания, политикам приходилось учитывать эти настроения, чтобы «держать руку на пульсе народной жизни, идти в ритме его биения» [1. С. 3]. Выступая от имени наций, в своих решениях съезды требовали модернизации Российского многонационального государства на принципах федерализма [2]. Причем съезды не всегда созывались по инициативе политических или общественных сил, в истории 1917 г. мы встречаемся с примерами стихийной самоорганизации. Так, на Украине Национальный конгресс (апрель, г. Киев) собрался в условиях, когда Центральная рада еще находилась в стадии становления, подготовительный процесс был недолог и не особенно содержателен, но его результаты превзошли все ожидания. Современники называли съезд «великим порывом», «великим национальным собранием», «воодушевленной поддержкой» идей автономии и федерализации.

В резолюциях съезда четко прозвучало требование переустройства России на автономно-федеративных началах и защиты прав национальных меньшинств. Среди других решений важной стала идея о необходимости налаживания контактов между народами России с целью интеграции на базе общих представлений о путях модернизации государственного устройства и национальных отношений: «Украинский национальный съезд поручает Центральной раде проявить как можно скорее инициативу в деле создания прочного союза народов России, которые, как и украинцы, требуют национально-территориалыной автономии на основаниях демократической Российской республики» [3. 3. С. 137]. Последущая работа по внутренней организации Рады и поиски соглашения с Временным правительством заслонили указанную проблему. Планируемый съезд народов долго откладывался и открылся только в сентябре 1917 г.

Цель исследования состоит в том, чтобы проанализировать событие не только с точки зрения солидарности этнических элит в 1917 г. по вопросам реформирования государственного устройства, но в то же время как один из этапов в эволюции их воззре- ний; рассмотреть предложение этническими элитами федерального варианта трансформации страны как одну из альтернатив в историческом развитии в начале XX в., как способ утвердить равноправие народов в многонациональной стране. Важнейшими источниками для анализа деятельности съезда стали материалы государственного архива высших органов власти и управления Украины (фонд Центральной рады), воспоминания политических деятелей тех лет, материалы средств массовой информации.

Основными акторами процесса федерализации как варианта трансформации государственного устройства России в 1917 г. были политики из этнических регионов страны. Созванный Центральной радой, съезд народов в Киеве во многом был делом личной инициативы М.С. Грушевского, так как отражал глубокое убеждение украинского лидера о том, что переустройства России на началах федерализма Украина может достичь лишь в союзе с другими народами страны. Вспоминалось при этом, что прецеденты совместных действий уже были, например, в годы Первой русской революции в деятельности парламентского клуба автономистов-федералистов. Эту преемственность подчеркивал также П.Н. Милюков, указывая, что «созыв съезда народов находился в... связи с пропагандой автономистов-федералистов первой Государственной Думы» [4. С. 99].

Форма представительства на съезд была выбрана инициативным бюро по его подготовке и предполагала приглашение всех национальных и областных организаций, политических партий, признающих федеративный принцип. Они получили право прислать по 10 представителей независимо от численности. Общее количество депутатов, прибывших на съезд, - 93 человека, в их числе белорусы, грузины, эстонцы, евреи, латыши, литовцы, поляки, румыны, татары, русские (от партии эсеров), а также казаки [5. Л. 1]. К акции присоединились Союз горских народов Северного Кавказа и Дагестана, ташкентские мусульманские организации, томская конференция сибирских общественных организаций, якутский союз федералистовтрудовиков и др. [6. С. 142]. Со съездом связывались большие надежды. Он должен был показать: вопервых, широкую поддержку требования национально-территориальной автономии в федеративной России; во-вторых, продемонстрировать распространенность лозунга в самой разной среде - его адептами 
были не только разные народы, но также разные политические партии и организации вплоть до женских (показателен факт участия в работе сьезда представителей женского татарского комитета в тот период, когда процесс эмансипации женщин, тем более в мусульманском мире, не стал всеобъемлющим) [5. Л. 1].

В своих воспоминаниях М. Грушевский достаточно много внимания уделяет съезду народов, называя его «светлым и радостным моментом международного братанья» [6. С. 137-138]. Важно подчеркнуть, что съезд продемонстрировал появление еще одной силы на политической арене - объединения негосударственных народов, также дал возможность выработать программу совместных действий и не исключал перспектив ее реализации, особенно на ожидаемом Учредительном собрании. Акция не осталась без внимания центральной власти, приславшей своего представителя в лице М.А. Славинского. Но не будем преувеличивать этот факт и расценивать его как изменение позиций Временного правительства относительно лозунга федерализма. По свидетельству и Грушевского и Милюкова, приезд Славинского был проявлением его личной инициативы и интереса А. Керенского к съезду. Сам М.А. Славинский объяснил свое участие в работе съезда так: «...без определенных полномочий, скорее в роли наблюдателя, чем участника» [7. C. 52]. С другой стороны, появление делегата от Временного правительства означало фактическое признание съезда народов. Недаром Грушевский в программной речи на заседании 10 сентября отметил это как положительный факт, как знак некоторого поворота в отношении Временного правительства к идеям федерализма [8. 12 сентября].

Объединяющим началом для всех участников съезда было требование федерализации. «В этом смысле у нас был общий язык с самого начала», - отмечал М. Грушевский в заключительной речи [5. Л. 6]. Однако развернувшаяся на конгрессе полемика продемонстрировала отличия в трактовке национального вопроса и проблем самоопределения с точки зрения разных партий и групп отдельных национальностей. Указанные разногласия стали продолжением дискуссий, развернувшихся в первой половине 1917 г. на I Общекавказском мусульманском съезде (апрель, Баку), I Всероссийском съезде мусульман (май, Москва), съездах отдельных мусульманских народов [9. С. 144-145]. Так, например, одна часть делегатов на съезде мусульман поддерживала идею федерализма, другая, «учитывая дисперсность расселения тюркских народов, выступала за реализацию проекта культурно-национальной автономии» [Там же]. Наиболее явно на Съезде народов в Киеве различие подходов проявилось в дискуссиях еврейских делегатов - сторонников и противников идеи отдельного еврейского государства в Палестине. Литовская делегация также включала в себя сторонников полной самостоятельности. Они определили свою позицию как отличную от установок Съезда народов, но не уклонились от его работы, а выразили желание участвовать в обсуждении вопроса о реформировании России на федеративных принципах, в отличие от представителей польского Демократического централа и ППС (леви- цы), которые отказались от участия в конгрессе исходя из постулата о полной независимости Польши.

В полемике киевского съезда относительно трактовки смысла федерации также выявились противоречия. Если для Грушевского и большинства делегатов федерация - это форма объединения государства для защиты и представительства своих общих интересов, то делегаты от ППС (левицы) утверждали, что федерация - только этап к полной самостоятельности. Решение проблемы в таком ключе было неприемлемо для М.С. Грушевского, так как отвергало его принципиальные взгляды, поэтому значение программной речи на заседании съезда 10 сентября заключалось в том числе в стремлении отмежеваться от польской позиции [8. 12 сентября].

Результатом бурного обсуждения проблем самоопределения на съезде стало принятие нескольких резолюций, отметим их наиболее значимые формулировки. Необходимость реформирования государства на началах национально-территориальной автономии и федеративного союза мотивировалась исходя из комплекса причин. Среди них:

1) природно-климатическое и экономическое разнообразие регионов огромной страны;

2) различие хозяйственной жизни народов;

3) необходимость создания быстрореагирующего аппарата управления;

4) потребность в механизме защиты от государственных переворотов путем захвата центральных учреждений - монополистов власти.

Представлялось также, что именно децентрализация станет спасением от разрухи на фронте и в тылу [5. Л. 1-2].

Среди решений съезда выделим признание необходимости защиты прав национальных меньшинств. Единственной формой реализации этого требования должна была стать национально-персональная автономия: «Исходя из того, что: 1) полное территориальное разграничение населяющих Россию национальностей невозможно, что среди них есть национальности, не составляющие ни в какой области большинства населения; 3 ) что национально-территориальная автономия не дает полного разрешения проблем национальных меньшинств, съезд народов постановил: каждая из населяющих Россию национальностей имеет право на национально-персональную автономию» [Там же. Л. 2].

Таким образом, решения съезда воплотили в себе убеждение Грушевского, что только комбинация территориального и персонального принципов дают решение национального вопроса, персональная автономия означает «конструирование нации в публично-правовой союз, охватывающий всех ее членов на всем пртяжении государства» [Там же]. Именно идентичность подходов дает основание предполагать, что идеи Грушевского как инициатора и вдохновителя съезда, его активного участника стали основой принятия подобных резолюций. Факт принятия резолюции о национально-персональной автономии показателен, так как не только определил подходы к проблеме лидеров украинского национального движения, но и показал взаимопонимание и 
поддержку со стороны других национальных организаций, а также стал почвой для перспективных действий по конституционному оформлению прав меньшинств и экстерриториальных народов. Отмечу при этом следующее обстоятельство. Формулировка резолюции съезда о персональной автономии не исключала возможности того, чтобы объединить в одно публично-правовое целое многочисленных украинцев, живущих вне пределов этнографической Украины. Грушевский еще в марте 1917 г. налаживает контакты подобного рода и обращается через прессу к украинцам вне Украины, призывает их к сотрудничеству, к участию в движении на Украине, утверждая, что важны и моральная поддержка из всех уголков страны, и любая информация о жизни и проблемах украинцев из диаспоры [10]. Как ответ на призыв и как надежда на помощь Центральной рады и в ее адрес и в адрес лично Грушевского посыпались письма и обращения. Так, «Обращение Рады Саратовской украинской громады от 23 мая 1917 г.» извещает о поездке украинцев из Саратовской губернии в Киев, чтобы «проникнуться украинским патриотизмом и привнести его в сердце своих односельчан... чтобы они приехали домой с энтузиазмом, которым проникнут народ на Украине» [11. Л. 1]. Таким образом, основы для кооперации всех украинцев России в публично-правовой союз закладывались в 1917 г., но вот в законе от 9.01.1918 г. они не наши отражения, и право украинцев, подобно другим национальным меньшинствам, кооперироваться с соплеменниками, живущими вне пределов Украины, не было нормировано.

Конгресс народов в числе обсуждаемых вопросов рассмотрел проблему языков. Равноправность всех языков как основного средства коммуникации в частных отношениях была признана однозначно, но за русским закреплено общефедеративное значение «для отношений центральных органов федеративных единиц с центральными органами федерации и между собой» [5. Л. 4]. Однако это не означало преимуществ русского языка, по решению съезда принцип равности должен быть проведен повсеместно (в суде, школе, церкви, других учреждениях) и основан на желании заинтересованных в общении сторон.

К преобразованию России в федерацию автономных единиц как главному требованию съезда народов звали, кроме всего прочего, события Первой мировой войны. Оккупированным Германией областям Литвы, Латвии, Белоруссии грозило отделение от основной этнографической территории. Исходя из этой опасности, съезд настоятельно обращается к Временному правительству провозгласить в законодательных актах автономию упомянутых территорий и право их учредительных собраний самим выбирать форму самоопределения вплоть до признания независимости государств (в такой постановке вопроса речь шла, например, о Литве, так как I Всероссийский литовский сейм в Петрограде в июне 1917 г. высказался за образование суверенного Литовского государства). При этом непреложными признавались соблюдение этнографических границ и учет волеизъявления населения регионов [5. Л. 2, 2 об., 3].
Касаясь механизма реализации программы, намеченной съездом, последний высказался за синтез двух путей: во-первых, необходима внутренняя работа народов по созыву местных Учредительных собраний; во-вторых, необходима взаимная деятельность в сотрудничестве с органами Временного правительства. Его представитель М.А. Славинский в своем выступлении благожелательно отнесся к проекту федерализации России, утверждая, что «в России единственной формой, которая обеспечит и политические, и национальные свободы, является форма автономного строя, а для всего государства - автономнофедеративная форма» регионов [8. 10 сентября]. При этом подчеркну, что Славинский не выражал точку зрения всего правительства, скорее, это его личная позиция, но, выступая как представитель центральной власти, он усиливал еще сохранявшуюся надежду на мирное решение проблем децентрализации через соглашение с Петроградским кабинетом, что позволило бы избежать насилия и кровопролития, создало бы правовые основы федерации, а не стало бы результатом захватных мер, непосредственных акций.

Стремление к сотрудничеству с Временным правительством, которым пронизаны документы конгресса народов, исходило из понимания того, что без средоточия будущей федерации в лице России о самой федеративной организации вряд ли может идти речь. По мнению Славинского, инициаторы форума руководствовались следущими мыслями: «...постепенно, мирным путем достичь своего национальногосударственного оформления - приблизительно таким способом, как его достигли английские доминионы, не выходя из пределов Британского объединения» [7. С. 55]. Основываясь на этих мотивах, съезд указал Временному правительству на необходимость «реорганизовать существующее особое совещание по областной реформе в особый Совет национальностей при Временном правительстве, как орган защиты интересов народностей», полагая, что он сможет дать поддержку и авторитетные указания правительству как по внутреннему переустройству России, так и обеспечить ее внешнюю безопасность во время войны. Помимо сотрудничества с Временным правительством ставилась задача кооперации усилий самих наций, для этого был организован Совет народов с целью «разработки и проведения в жизнь всех тех мероприятий, которые окажутся необходимыми при осуществлении задач национального и областного автономно-федеративного строительства» [5. Л. 4 об].

Однако последующие события, в первую очередь выступление делегации Съезда народов на Демократическом совещании, показали иллюзорность надежд на решение национального вопроса в России путем соглашения. На нем национальный вопрос был воспринят как второразрядная проблема под свист, шиканье и насмешки при полупустых трибунах. Общее настроение совещания по отношению к национальным чаяниям выразил представитель горских народов Северного Кавказа, сказав, что выдвижение вопроса о правах отдельных частей государства есть проявление только недостаточного чувства гражданских обязанностей [6. С. 147]. Подобная неприязнь, которую проявила по отношению к нацио- 
нальному вопросу российская демократия на Демократическом совещании, вызвала в украинских кругах, по словам Грушевского, «желание отказаться от всяких счетов с ней и идти своей дорогой», поставив во главу угла вопрос о самоорганизации и созыве Учредитального собрания, не оставляя в стороне контактов с другими народами России, стремящимися к ее федеративному переустройству. Позднее П.Н. Милюков отмечал, что «что стремление самим решать свою судьбу после недружелюбной встречи на Демократическом совещании... усилилось» [4. С. 102].

Таким образом, о создании Совета Национальностей при Временном правительстве при явном негативном отношении последнего не могло быть и речи. Не успел развернуть свою работу и Совет народов события октября 1917 г. кардинально изменили ситуацию. Они стали поводом для актуализации вопроса об объединении усилий народов России, но теперь уже с целью борьбы с большевизмом. Таким образом, с точки зрения получения реального, значимого результата съезд дал немного: в условиях сентября 1917 г. был скорее данью национальной романтике. Именно такую оценку в итоге дает съезду Грушевский, понимая, что съезд запоздал. Российская демократическая власть, с которой и собирались федерироваться негосударственные народы, после корниловского выступления явно находилась в состоянии агонии. Возможность же федерации без нее исключалась, так как русская нация во главе с демократическим правительством представлялась средоточием будущего федеративного строя. «Без нее, - писал ученый, сами негосударственные народы не могут построить этой федерации» [6. С. 142]. Это обстоятельство в качестве ведущего называет и М.А. Славинский, анализируя причины безрезультативности съезда: «Великорусским отношением к делу съезда предрешена была и участь его планов и его работы» [7. С. 52].

Резюмируем вышесказанное. В политическом дискурсе по проблемам трансформации государственного устройства в России в 1917 г. активно участвовали представители этнических элит многонациональной страны (М. Грушевский, А.-3. Вали- дов и др.), предпочитая не ждать Учредительного собрания, активно предлагая федеративные проекты взаимодействия с центром. Съезд народов России в Киеве в сентябре 1917 г. был созван по инициативе Украинской центральной рады и ее лидера М.С. Грушевского, он объединил усилия народов России, отстаивающих идею децентрализации государственного устройства на автономно-федеративных началах и, таким образом, реализовал проект горизонтальных связей между этносами многонационального Российского государства и их политическими и общественными объединениям. Автономия при этом выступала формой организации национальной жизни в рамках региона (национально-территориальная автономия), а федерация - средством объединения страны. На съезде была подчеркнута важность защиты прав национальных меньшинств и экстерриториальных народов через конструирование национально-персональной, экстерриториальной автономии. В случае самоопределения народов в форме независимости утверждалась важность референдумов для определения границ. Временному правительству предлагалось обратить особое внимание на национальные потребности, с этой целью сформировать при нем специальный орган. Обращение к Временному правительству подчеркивает «диалоговую позицию» [9. С. 146] и Съезда в Киеве, и лидеров Центральной рады. Однако потенциал Съезда народов не был реализован и в силу отсутствия поддержки со стороны Временного правительства и централистической позиции значительной части российской демократии; время его проведения также оказалось важным фактором - со своим проектом модернизации съезд опоздал. В сентябре 1917 г. центральная российская власть сама находилась в сложнейших условиях, переживая институциональный кризис, когда на повестку дня был поставлен вопрос ее дальнейшего существования. В то же время указанные обстоятельства не умаляют значения съезда в Киеве: он продемонстрировал безусловное стремление народов России к переустройству страны на автономно-федеративных началах.

\section{ЛИТЕРАТУРА}

1. Грушевский М.С. Свободная Украина. Статьи последних дней (март-апрель 1917 г.). Киев, 1917.17 с. На укр. яз.

2. Файзрахманов А.Ш. Вопросы федеративного устройства России в решениях национальных съездов в 1917 г. // Вестник Тамбовского университета. Сер. Гуманитарные науки. 2010. Вып. 7 (87). С. 255-259.

3. Революция и национальный вопрос. Документы и материалы по истории национального вопроса в России и СССР в ХХ в. : в 4 т. М., 1930. Т. 3: 1917 год. Февраль-октябрь. 504 с.

4. Милюков П.Н. История второй русской революции. София : Российско-Болгарское книгоиздательство, 1921. Т. 1, вып. 3: Агония власти. $308 \mathrm{c}$.

5. ЦГАВО Украины. Ф. 1115: Центральная рада. Оп. 1. Д. 7.

6. Грушевский М.С. Воспоминания // Киев. 1989. № 11. С. 113-155. На укр. яз.

7. Славинский М.А. Национально-государственная проблема в СССР. Париж, 1938. 75 с.

8. Киевская мысль. 1917.

9. Красовицкая Т.Ю. Этнические элиты о формах федеративного устройства России (1917-1929) // Мир большого Алтая. 2017. № 3 (2). С. 139-157.

10. Вести из украинской Центральной рады в Киеве. 1917. 19 марта.

11. ЦГАВО Украины. Ф. 1115: Центральная рада. Оп. 1. Д. 60.

Статья представлена научной редакцией «История» 14 августа 2018 г. 


\section{ETHNIC MOBILIZATION IN 1917: THE CONGRESS OF THE PEOPLES OF RUSSIA AND ITS IDEAS ON THE TRANSFORMATION OF THE STATE SYSTEM}

Vestnik Tomskogo gosudarstvennogo universiteta - Tomsk State University Journal, 2018, 437, 143-147.

DOI: $10.17223 / 15617793 / 437 / 20$

Larisa A. Kutilova, Siberian Federal University (Krasnoyarsk, Russian Federation). E-mail: kutilovala@rambler.ru

Keywords: 1917; Congress of Peoples; ethnic mobilization; modernization projects; federalism.

The aim of this research is to study the role of ethnic elites in the political discourse of 1917 on the problems of the Russian state structure transformation. The research objectives are connected with the analysis of the Congress of the Peoples of Russia in Kiev in September 1917 and the stages of evolution of the views of national leaders (such as M. Hrushevsky, Zeki Velidi Togan and others) on the issues of reforming the multiethnic country's state structure. The author used materials of the Central State Archives of Supreme Bodies of Power and Government of Ukraine (the Central Rada Fund), memoirs of politicians of those years and newspaper materials. The article analyzes in detail the course of work of the congress in Kiev, membership of representatives (emphasizing the participation of a female Tatar Committee), the topics discussed at the congress, its resolutions. The author pointed out that the unifying principle for the congress participants was the requirement of federalization, but, at the same time, during the congress there arose a controversy on the problems of self-determination (in particular, federalization or complete independence for Lithuania, Polanld; the issue of establishing an independent Jewish state; forms of self-government for dispersed peoples, etc.). Also it has been found that the delegates understood the meaning of the federation in different ways. As a result of the research, the author came to the following conclusions. Representatives of ethnic elites of the multinational country actively offered federal projects of cooperation with the center, instead of attending to wait for the Constituent Assembly. The Congress of the Peoples of Russia in Kiev demonstrated the emergence of a new force in the political stage - unification of non-state peoples requiring federalization. It gave an opportunity to endorse a program of concerted actions and did not exclude its implementation, especially at the expected Constituent Assembly. The author emphasized that according to the adopted resolutions, the federation within the framework of the country's reform was meant to become a means of its unification, and autonomy was to be a form of a national life arrangement within the region (national territorial autonomy). The author summarized that the Congress of the Peoples in 1917 executed the project of horizontal links among the ethnoses of the multinational Russian state and their political and public associations. The project reflected the dialogue position of the majority of the country's ethnic elites towards the central government in the period until October 1917. The author emphasized the importance of the idea of the congress on the protection of the rights of national minorities and extraterritorial peoples by means of the construction of a national personal (extraterritorial) autonomy. However, the author stressed that the potential of the Congress of the Peoples was not realized; by analyzing considerations, the author came to a conclusion that this happened due to the lack of support from the Provisional Government and the centralist position of a significant part of Russian democracy. The time of its holding also proved to be an important factor - with its project of modernization of the country the Congress was late and was ultimately only a "tribute to the national romance". In September 1917, the central Russian government itself was in crisis: the issue of its existence was put on the agenda. The author also focused on the significance of the Congress in Kiev: she demonstrated the unconditional desire of the peoples of Russia to reorganize the country on a federative basis in the period before the Bolsheviks came to power.

\section{REFERENCES}

1. Grushevskiy, M.S. (1917) Svobodnaya Ukraina. Stat'i poslednikh dney (mart-aprel’ 1917 g.) [The Free Ukraine. Articles of recent days (March April 1917)]. Kiev: [s.n.]. (In Ukrainian).

2. Fayzrakhmanov, A.Sh. (2010) Voprosy federativnogo ustroystva Rossii v resheniyakh natsional'nykh s”ezdov v 1917 g. [Questions of the federal structure of Russia in the decisions of the national congresses in 1917]. Vestnik Tambovskogo universiteta. Ser. Gumanitarnye nauki - Tambov University Review. Series Humanities. 7 (87). pp. 255-259.

3. Levin, I. et al. (1930) Revolyutsiya i natsional'nyy vopros. Dokumenty i materialy po istorii natsional'nogo voprosa v Rossii i SSSR v XX v.: $v 4 t$. [Revolution and the national question. Documents and materials on the history of the national question in Russia and the USSR in the twentieth century: in 4 vols]. Vol. 3. Moscow: Kommunisticheskaya akademiya.

4. Milyukov, P.N. (1921) Istoriya vtoroy russkoy revolyutsii [The history of the second Russian revolution]. Vol. 1. Is. 3. Sofia: RossiyskoBolgarskoe knigoizdatel'stvo.

5. Central State Archives of Supreme Bodies of Power and Government of Ukraine. Fund 1115: Tsentral'naya rada [Central Rada]. List 1. File 7.

6. Grushevskiy, M.S. (1989) Vospominaniya [Memories]. Kiev. 11. pp. 113-155. (In Ukrainian).

7. Slavinskiy, M.A. (1938) Natsional'no-gosudarstvennaya problema v SSSR [The national-state problem in the USSR]. Paris: La Seconde.

8. Kievskaya mysl'. (1917).

9. Krasovitskaya, T.Yu. (2017) Etnicheskie elity o formakh federativnogo ustroystva Rossii (1917-1929) [Ethnic elites about the forms of federal structure of Russia (1917-1929)]. Mir bol'shogo Altaya. 3 (2). pp. 139-157.

10. Vesti iz ukrainskoy Tsentral'noy rady v Kieve. (1917) 19 March.

11. Central State Archives of Supreme Bodies of Power and Government of Ukraine. Fund 1115: Tsentral'naya rada [Central Rada]. List 1. File 60. 